\title{
Margaret McCartney: Why less confidence may be a good thing
}

\author{
Margaret McCartney general practitioner, Glasgow
}

In any of the exams I've ever sat I've never been asked, "What don't we know?"

Hormone replacement therapy (HRT) is in the news. The papers say that GPs aren't prescribing it enough. ${ }^{12}$ Further, the National Institute for Health and Care Excellence has said that its new advice on menopause is "to help GPs and other healthcare professionals to be more confident in prescribing HRT and women more confident in taking it."3

Confidence is an odd thing when combined with inevitable clinical uncertainty. When the evidence is explained, how do we know that more women will want HRT? How do we know that we should feel confident about prescribing it? When does it become clinically unreasonable to prescribe HRT? How about for the 20th year, to a 70 year old woman who smokes and has hypertension and a strong family history of breast cancer, who has had a possible transient ischaemic attack but says that she accepts the risks?

Medicine is prone to conflate a lack of knowledge with stupidity, academic inability, or laziness. "Be wrong but never in doubt" was a tip for medical school exams that, I'm ashamed to say, I cheerfully followed definitively. Wouldn't it have been better to ask, "How much more likely is it, do you think, that sitting patients forward and asking them to hold in full expiration will make clinically important aortic regurgitation audible?" Is this about tradition or evidence? Do you know? Do I?

There's a lovely graph that illustrates how confidence and knowledge vary with time. We start with lots of confidence and little knowledge and end up with more knowledge but less confidence. Another curve has yet to be added, of anxiety felt because of uncertainty, which probably starts high and then decreases, only to wax and wane with spikes and descents over time-related to what you see, what you think you see, and what your colleagues tell you they see.

We're good at setting up systems to get us to prescribe more, test more, do more. We're less inclined to generate systems that make explicit the uncertainties of what we're doing. We're even unsure, I think, about the best information to help individual patients make high quality choices. And we're unsure about how to do this in the pressure of a GP consultation or when people have reading or numeracy problems.

Part of improving risk literacy is about acknowledging doubt, margins of error, and whether the research available fits the patient we're applying it to. How certain are you, doctor? And how confident are you in that level of certainty? Less confidence may make for higher reliability, more thoughtful medicine, and better choices.

Competing interests: I have read and understood the BMJ policy on declaration of interests and declare the following interests: I'm an NHS GP partner, with income partly dependent on Quality and Outcomes Framework points. I've written two books and earn from broadcast and written freelance journalism. I'm an unpaid patron of Healthwatch. I make a monthly donation to Keep Our NHS Public. I'm a member of Medact. I'm occasionally paid for time, travel, and accommodation to give talks or have locum fees paid to allow me to give talks but never for any drug or public relations company. I was elected to the national council of the Royal College of General Practitioners in 2013 and am chair of its standing group on overdiagnosis. I have invested a small amount of money in a social enterprise, Who Made Your Pants?

Provenance and peer review: Commissioned; not externally peer reviewed.

Follow Margaret on Twitter, @mgtmccartney

1 Knapton S. Ignore health scares, HRT is safe, say scientists. Telegraph 2015 Oct 19 www.telegraph.co.uk/news/science/science-news/11938763/lgnore-health-scares-HRTis-safe-say-scientists.html.

2 Gregory A. It's official: HRT is NOT a danger to women as experts conclusively dismiss worries over safety. Mirror 2015 Oct 19. www.mirror.co.uk/news/technology-science/ science/its-official-hrt-not-danger-6658314.

3 National Institute for Health and Care Excellence. Menopause: diagnosis and management. NICE guidelines NG23. Nov 2015. www.nice.org.uk/guidance/ng23/chapter/Menopauseimplementation-getting-started.

Cite this as: BMJ 2015;351:h6321

๑) BMJ Publishing Group Ltd 2015 